\title{
HLA-B27 Antigen Measurement
}

National Cancer Institute

\section{Source}

National Cancer Institute. HLA-B27 Antigen Measurement. NCI Thesaurus. Code C100460.

The determination of the amount of HLA-B27 antigen present in a sample. 